\title{
The potential ecological impact of the exotic snail Pomacea canaliculata on the Thai native snail Pila scutata
}

\author{
Ratcha Chaichana $^{\mathrm{a}, \mathrm{b}, *}$, Thepbodee Sumpan ${ }^{\mathrm{a}}$ \\ a Department of Environmental Technology and Management, Faculty of Environment, Kasetsart University, \\ Chatuchak, Bangkok 10900 Thailand \\ b Centre for Advanced Studies in Tropical Natural Resources, NRU-KU, Kasetsart University, Chatuchak, \\ Bangkok 10900 Thailand
}

*Corresponding author, e-mail: fscircc@ku.ac.th

Received 10 Jul 2013

Accepted 22 Dec 2013

\begin{abstract}
The aims of this study were to compare food consumption, growth rates, time to reach food, and food preferences of the golden apple snail (Pomacea canaliculata) and the Thai native snail (Pila scutata). The eggs of the two species collected from natural habitats were hatched in the laboratory. Snails of one month were raised together and separately to determine growth rates and food consumption. It was found that the growth rate of $P$. canaliculata was significantly faster than that of $P$. scutata when both were raised together and when they were raised separately. Both snails grew better when raised separately. P. canaliculata consumed significantly more food than $P$. scutata. When raised separately, $P$. canaliculata crawled to food at a significantly faster rate than $P$. scutata. On average, $P$. canaliculata and P. scutata took $8.2 \pm 3.2$ and $15.1 \pm 3.1 \mathrm{~min}$, respectively, to reach the food offered. To test for food preferences, four local species of aquatic plants, namely Hydrilla verticillata, Nymphaea lotus, Salvinia cucullata, and Alternanthera triandra were provided to both snails. It was discovered that $P$. canaliculata consumed all the four different food species offered. In contrast, $P$. scutata tended to feed on $S$. cucullata rather than the other species. It is concluded that $P$. canaliculata was superior to $P$. scutata in terms of growth rates, food consumption, and was also non-selective for food and therefore there is no doubt that in a shared habitat, $P$. canaliculata will influence $P$. scutata.
\end{abstract}

KEYWORDS: invasive species, wetland, competition, food

\section{INTRODUCTION}

Among the 3500 non-native species introduced to Thailand, the golden apple snail (Pomacea canaliculata, Lamarck) appears to be one of the worst invasive species $^{1}$. It was introduced almost 30 years ago as a dietary protein supplement and as a pet in the ornamental aquatic animal industry. The spread of $P$. canaliculata in Thailand as a result of intentional and accidental introduction has caused enormous economic and ecological impacts ${ }^{2}$. P. canaliculata has invaded wetlands and paddy fields and destroyed agricultural produce, especially rice ${ }^{3}$ leading to economic losses and the use of chemical pesticides that also adversely alter aquatic ecosystems and impact human health ${ }^{4-7}$. It has been estimated that in Thailand alone, $P$. canaliculata has caused losses of at least 3000 million US dollars per year due to agricultural destruction ${ }^{1}$.

The impacts of $P$. canaliculata on aquatic vegetation have been relatively well studied ${ }^{6,8-11}$. In contrast, there is still much to know on how invasion by $P$. canaliculata may also affect other local fauna species in the area. For instance, in Thailand, populations of $P$. scutata, locally known as apple snail and similar to $P$. canaliculata in terms of size and shape, have decreased to an alarming degree ${ }^{12}$. The population reduction of this snail may be linked to the invasion by $P$. canaliculata in a shared habitat ${ }^{5}$. $P$. canaliculata may displace local snail species competing for food and space ${ }^{10}$. A recent study showed that $P$. canaliculata introduced to the Everglades, USA appeared to consume and grow more than the native $P$. paludosa resulting in greater rates of expansion ${ }^{11}$. In addition, any reduction of the local snail species may result from predation by $P$. canaliculata since a study in southern China in 2009 indicated that $P$. canaliculata caused significant mortality of all the early stages of the local five snails ${ }^{13}$. P. canaliculata may also be more adaptive to invaded habitat than local species particularly with respect to feeding behaviour and food preferences. P. canaliculata may be non-selective for food ${ }^{14}$ while local snail species may be food selective, thus lowering their chances to thrive 
in environments where food sources are limited.

Since there is still no scientific evidence documenting the reduction of Thai native species dwelling in areas invaded by the golden apple snail, this study aimed to investigate the potential impact of $P$. canaliculata on $P$. scutata with regard to food competition and growth rates. We also determined the time it took for snails to reach different food offered, together with their feeding behaviour and food preferences. The results reveal a competition for food between $P$. canaliculata and $P$. scutata and disclose that $P$. scutata is selective for their food source. An ecological understanding of non-indigenous and indigenous species will lead to proper management and conservation policies to protect local snail species, which otherwise may soon disappear from natural habitats.

\section{MATERIAL AND METHODS}

\section{Sampling $P$. canaliculata and $P$. scutata}

Eggs of $P$. canaliculata were collected from natural habitats at Kasetsart University, Bangkok $\left(13^{\circ} 50^{\prime} 52^{\prime \prime} \mathrm{N} 100^{\circ} 34^{\prime} 15^{\prime \prime} \mathrm{E}\right)$ whereas eggs of $P$. scutata were obtained from canals in a palm oil plantation in Plaiwas subdistrict, Kanchanadit district, Surat Thani province, southern Thailand $\left(9^{\circ} 09^{\prime} 56^{\prime \prime} \mathrm{N}\right.$ $\left.99^{\circ} 28^{\prime} 16^{\prime \prime} \mathrm{E}\right)$. The number of eggs per cluster of $P$. canaliculata ranged from 100-855, while the number of eggs per cluster of $P$. scutata was only 40 45. Eggs of $P$. scutata $(0.5 \mathrm{~cm}$ in diameter $)$ were bigger in size than those of $P$. canaliculata $(0.2 \mathrm{~cm})$. Eggs of $P$. canaliculata and $P$. scutata were different in colours, with those of $P$. canaliculata being pink whereas eggs of P. scutata were white. Eggs of both snails were incubated in separate containers at constant room temperature (approx. $30{ }^{\circ} \mathrm{C}$ ) in a laboratory of the Department of Environmental Technology and Management, Faculty of Environment, Kasetsart University, Bangkok, Thailand. After hatching, water spinach (Ipomoea aquatica) was used to feed both species before the snails were used in the experiments.

To test for food competition and growth rates, $P$. canaliculata and $P$. scutata at shell width of $1.0 \mathrm{~cm}$ and weight of $0.5 \mathrm{~g}$. (one month old) were raised in the laboratory under two sets of conditions in 21 cylindrical containers (raised together at a 1:1 ratio of $P$. canaliculata and $P$. scutata and secondly raised separately with one snail in each container). All snails were fed with water spinach (I. aquatica) daily $(24 \mathrm{~h})$. The water spinach provided was weighed before and after feeding of each snail. Measurement of growth rates (weight, shell height, and width) and food consumption of each snail was conducted every week. The experiment was repeated five times and lasted for five months. We also recorded the time it took for $P$. canaliculata and $P$. scutata to crawl to the food that was offered.

Selective behaviour for food between $P$. canaliculata and P. scutata was studied in the laboratory. We hypothesized that $P$. canaliculata is non-selective for food in comparison with $P$. scutata that is a foodselective snail. Four types of plants were used in the study as food sources, namely submerged ( $\mathrm{Hy}$ drilla verticillata), emergent (Nymphaea lotus), floating (Salvinia cucullata), and marginal (Alternanthera triandra). Approximately $2 \mathrm{~g}$ of each species was planted in containers ( 21 cylindrical containers) with aeration to avoid anaerobic conditions developing. Afterwards, one $P$. canaliculata $(0.5 \mathrm{~cm}$, one month old) was released in a container. A P. scutata specimen of the same size was also released in a separate container with four species of aquatic plants inside. Five replicates were used for validity testing of data and the experiments were conducted for one month. The growth rates of both snails and the amount of plants consumed were measured daily $(24 \mathrm{~h})$ from the beginning of the experiment. Observations on feeding behaviour between the two species were carried out after each food presentation.

We used EXCEL 2010 and SPSS Statistics 17.0 packages for statistical analyses. An F-test was applied to determine differences in food consumption, growth rate and the time taken between the two snail species to reach food. Values presented throughout are given as mean \pm standard deviation for the numbers of samples measured.

\section{RESULTS \\ Comparisons of food consumption, growth rates, and time to reach food}

The statistical analysis of food consumption and growth rates between $P$. canaliculata and $P$. scutata revealed that $P$. canaliculata consumed significantly more food and grew significantly better than $P$. scutata in conditions when both $P$. canaliculata and $P$. scutata were raised together and when they were raised separately (Table 1, Fig. 1, and Fig. 2). It was also found that the overall growth rates of $P$. canaliculata and $P$. scutata were better when they were raised separately compared with the growth rates when they were raised together.

When raised separately, $P$. canaliculata consumed three times as much food as $P$. scutata. It was also found that consumption of $P$. canaliculata and 

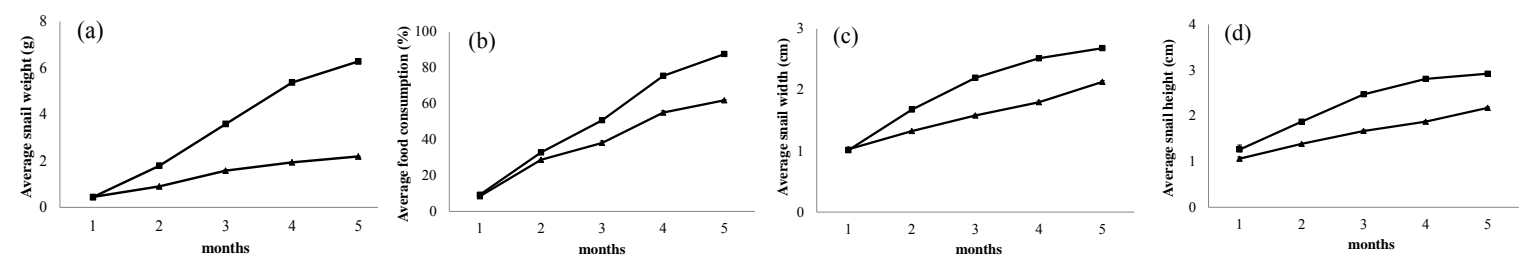

Fig. 1 Average food consumption and growth rates of $P$. canaliculata (black squares) and P. scutata (black triangles) when they were raised separately.
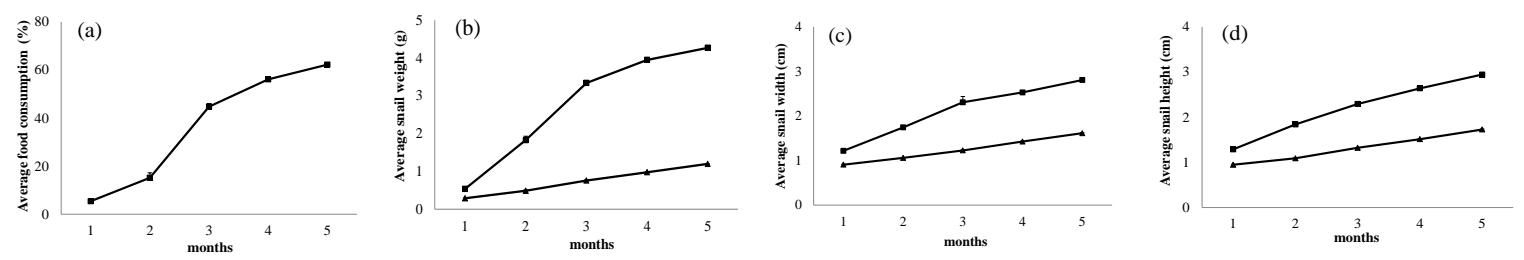

Fig. 2 Average food consumption and growth rates of $P$. canaliculata (black squares) and $P$. scutata (black triangles) when they were raised together.

Table 1 Growth rates of $P$. canaliculata and $P$. scutata when raised together and raised separately for two months $(n=5)$.

\begin{tabular}{lcc}
\hline Measurement & P. canaliculata & P. scutata \\
\hline Weight (g) & & \\
$\quad$ Raised separately & $3.2 \pm 2.1$ & $1.33 \pm 0.65$ \\
$\quad$ Raised together & $2.6 \pm 1.4$ & $0.69 \pm 0.31$ \\
width (cm) & & \\
$\quad$ Raised separately & $1.94 \pm 0.62$ & $1.51 \pm 0.37$ \\
$\quad$ Raised together & $2.04 \pm 0.66$ & $1.21 \pm 0.24$ \\
Height (cm) & & \\
$\quad$ Raised separately & $2.20 \pm 0.68$ & $1.57 \pm 0.38$ \\
$\quad$ Raised together & $2.12 \pm 0.58$ & $1.28 \pm 0.27$ \\
\hline
\end{tabular}

Table 2 Food consumption (g) of $P$. canaliculata and $P$. scutata when raised together and raised separately for two months $(n=5)$.

\begin{tabular}{lccc}
\hline & P. canaliculata & P. scutata & $p$ value \\
\hline Raised separately & $1.80 \pm 0.99$ & $0.58 \pm 0.49$ & $<0.05$ \\
Raised together & \multicolumn{2}{c}{$1.7 \pm 1.1$} & \\
\hline
\end{tabular}

P. scutata together was lower than when raised separately (Table 2). In addition, when raised separately, $P$. canaliculata crawled to food at a significantly faster rate than $P$. scutata. In contrast, when raised together, the length of time to reach food for $P$. canaliculata and for $P$. scutata was not significantly different. However, the length of time taken to reach food by $P$. scutata was significantly different when raised separately and raised together but not for $P$. canaliculata (Table 3).
Table 3 Length of time (min) taken to reach food for $P$. canaliculata and $P$. scutata when raised together and raised separately for two months $(n=5)$.

\begin{tabular}{lccc}
\hline & P. canaliculata & P. scutata & $p$ value $^{\mathrm{b}}$ \\
\hline Raised separately & $8.8 \pm 3.6$ & $19.8 \pm 4.3$ & 0.04 \\
Raised together & $8.2 \pm 3.2$ & $15.1 \pm 3.1$ & 0.67 \\
$p$ value $^{\mathrm{a}}$ & 0.23 & $<0.05$ & \\
\hline
\end{tabular}

${ }^{\text {a }}$ Comparison within species.

${ }^{\mathrm{b}}$ Comparison between species.

Table 4 Consumption (in g) by $P$. canaliculata and $P$. scutata feeding on $H$. verticillata, N. lotus, S. cucullata and A. triandra $(n=3)$.

\begin{tabular}{lccc}
\hline Type of plant & P. canaliculata & P. scutata & $p$ value \\
\hline H. verticillata & $0.47 \pm 0.04$ & $0.37 \pm 0.04$ & 0.97 \\
S. cucullata & $0.58 \pm 0.03$ & $0.51 \pm 0.03$ & 0.62 \\
A. triandra & $0.53 \pm 0.03$ & $0.35 \pm 0.02$ & 0.12 \\
N. lotus & $0.51 \pm 0.04$ & $0.39 \pm 0.01$ & $<0.05$ \\
\hline
\end{tabular}

\section{Rates of aquatic macrophyte consumption}

Four types of aquatic macrophytes, namely $H$. verticillata, N. lotus, S. cucullata and A. triandra were offered to $P$. canaliculata and $P$. scutata. It was found that both snail species could consume all plants offered. In addition, the consumption rates by $P$. canaliculata and $P$. scutata when feeding on $H$. verticillata, S. cucullata and $A$. triandra were not significantly different. However, there was a significantly greater amount of $N$. lotus consumed by $P$. canaliculata than by $P$. scutata (Table 4). 
Table 5 F-test for food preferences of $P$. canaliculata and $P$. scutata. Data in each row are $p$ values $(n=3)$.

\begin{tabular}{lcccc}
\hline & H. verticillata & S. cucullata & A. triandra & N. lotus \\
\hline P. canaliculata & & & & \\
H. verticillata & 1.00 & 0.29 & 0.31 & 0.74 \\
S. cucullata & - & 1.00 & 0.96 & 0.46 \\
A. triandra & - & - & 1.00 & 0.50 \\
N. lotus & - & - & - & 1.00 \\
P. scutata & & & & \\
H. verticillata & 1.00 & 0.59 & $0.01^{*}$ & $0.00^{*}$ \\
S. cucullata & - & 1.00 & $0.05^{*}$ & $0.00^{*}$ \\
A. triandra & - & - & 1.00 & $0.03^{*}$ \\
N. lotus & - & - & - & 1.00 \\
\hline
\end{tabular}

* Significant differences among data at $p<0.05$.

$P$. canaliculata was non-selective for food, consuming similar levels of $H$. verticillata, N. lotus, S. cucullata, and A. triandra (Table 5). P. scutata however tended to consume preferentially $S$. cucullata rather than the other plant species offered.

\section{DISCUSSION}

According to our experiments, it could be stated that non-indigenous $P$. canaliculata is a successful invader as it consumed more food, grew better, reached food faster, and was non-selective for food in comparison to the native species, P. scutata (Fig. 1 and Fig. 2). The results clearly show that when raised separately, non-indigenous $P$. canaliculata consumed more (three times) and grew faster (twice) than P. scutata, compared to the Thai native snail that ate less and grew at a lower rate. Our study is in agreement with a study done in the USA showing that the non-native species $P$. insularum and $P$. canaliculata tend to eat more and grow faster than the native $P$. paludosa $a^{11}$. When raised together, the consumption and growth rates of both species were lower than when raised separately. The reduction in consumption and growth rates of both species when raised together could be linked to competition for food among species and perhaps linked to a space limitation when the two snails were raised in the same container. However, the food consumption and growth rates of $P$. canaliculata still tended to be higher and better than those of $P$. scutata when the two snails were raised together. Accordingly, in a shared habitat, it is likely that nonnative $P$. canaliculata may displace the indigenous $P$. scutata. It is also interesting that the gap between growth rates (measured by weight) of the two snails was bigger when snails become larger. $P$. canaliculata may reach maturity faster than $P$. scutata and thus have a better chance to reproduce and expand its population.

The feeding patterns of $P$. canaliculata and $P$. scutata when offered food were different. P. canalicu- lata always moved quickly to the food regardless of whether the individual had been raised separately or raised together with the other species. This was indicated by the times taken to reach food by $P$. canaliculata which were not significantly different regardless of the rearing conditions. When $P$. canaliculata and $P$. scutata were raised separately, on average, $P$. canaliculata took about nine minutes to reach food offered, which was faster than for $P$. scutata as the latter species took much longer to reach food (20 min). A slower time to reach food for $P$. scutata when raised individually indicates that it does not have to compete for food with other snails. It is also interesting that when $P$. canaliculata and $P$. scutata were raised together, $P$. scutata took less time to reach food compared with the time for $P$. scutata raised separately. This may have been the result of competition for food experienced by the native species when living with non-indigenous species.

$P$. canaliculata and $P$. scutata appears to exhibit different food preferences. $P$. canaliculata did not show any preferences among the different food plants offered whereas $P$. scutata fed on preferred plants. $P$. canaliculata was non-selective for food since the amount of each plant species consumed was not different. $P$. canaliculata appears to feed indiscriminately regardless the plant species ${ }^{14}$. Other study also showed that when different food types were offered, $P$. canaliculata grazed heavily on both species of macrophytes provided ${ }^{10}$. A study conducted in Laos also supported this study that the absence of aquatic plants in wetlands may be linked to the presence of $P$. canaliculata as this species can eat almost any plant $^{15}$. In contrast, $P$. scutata tended to be selective for food as it preferred $S$. cucullata over other species. Our study is in agreement with that of Carlsson ${ }^{15}$ who reported that $P$. canaliculata had a strong negative effect on the growth and biomass of the preferred plants $S$. cucullata and L. adscendens that had been grazed down to very low levels. According to local residents, S. cucullata and L. adscendens have disappeared from the Vientiane wetlands since the snail was introduced in $1992^{15}$. Substantial grazing by P. scutata on $S$. cucullata may likely have been due to the softness of this plant species or perhaps it was easier to eat since it is a floating type of vegetation.

As they are non-selective eating snails, nonindigenous $P$. canaliculata may spread easily and survive better in natural habitats than other species such as the food-selective $P$. scutata. The food-selective behaviour of $P$. scutata was also confirmed in the study of Wood ${ }^{16}$ who reported that $P$. canaliculata was not only a plant feeder but also had a profound effect on 
the freshwater bryozoan community through feeding, whereas the indigenous apple snail ( $P$. scutata) does not graze on bryozoans. Our findings also reflect the fact that $P$. canaliculata is a non-food-selective snail that may cause a substantial impact on wetland vegetation that could result in a change from a plantdominated state to a turbid phase dominated by phytoplankton ${ }^{15}$.

Furthermore, it was obvious from direct observation that both $P$. canaliculata and $P$. scutata showed similar feeding behaviour as they first ate a floating plant, S. cucullata and then A. triandra, followed by $N$. lotus, and then by $H$. verticillata last as it is a submerged plant. This may have been due to easier accessibility to floating plants than submerged plants, thus resulting in lower consumption of $H$. verticillata.

In conclusion, the golden apple snail ( $P$. canaliculata) was superior to the Thai native snail ( $P$. scutata) in terms of food consumption, growth rate, time to reach food, and food preference. In a shared habitat, Thai native snails that eat less, move slowly to reach food, and are selective for food could be affected by golden apple snails, thus leading to a reduction in native snail populations. To conserve populations of $P$. scutata, the control of $P$. canaliculata in a shared habitat must be considered together with the promotion of pristine wetlands that consist of a great variety of aquatic macrophytes that can support the survival of local species like $P$. scutata.

Acknowledgements: We thank the Research and Development Institute of Kasetsart University (KURDI) for financial support. We are also grateful to the Centre for Advanced Studies in Tropical Natural Resources (NRUKU), Kasetsart University for partial support.

\section{REFERENCES}

1. Vidthayanon C (2006) The Worse Invasive Aquatic Species of Thailand. In a report of a meeting of invasive species. Office of Natural Resources and Environmental Policy and Planning, Ministry of Environment and Natural Resource. 31 August 2006, Bangkok, pp 67-74, (in Thai).

2. Keawjam RS (1986) The apple snails of Thailand: distribution, habitats and shell morphology. Malacol Rev 19, 61-81.

3. Cowie RH (2002) Apple snails (Ampullariidae) as agricultural pests: their biology, impacts, and management. In: Barker GM (ed) Molluscs as Crop Pests, CABI, New York, pp 145-92.

4. Anderson B (1993) The Philippine snail disaster. Ecologist 23, 70-2.

5. Halwart M (1994) The golden apple snail Pomacea canaliculata in Asian rice farming systems: present impact and future threat. Int J Pest Manag 40, 199-206.

6. Naylor R (1996) Invasions in agriculture: assessing the cost of the golden apple snail in Asia. Ambio 25, 443-8.

7. Janyapeth S, Archawakom T (1999) Biology of the alien apple snails. In: The Alien Apple Snail, Thai Ministry of Agriculture and Cooperatives, Pailin Hotel, Phitsanulok, Thailand, pp 1.1-1.15. (in Thai).

8. Carlsson N, Kestrup A, Martensson M, Nystrom P (2004) Lethal and non-lethal effects of multiple indigenous predators on the invasive golden apple snail (Pomacea canaliculata). Freshwat Biol 49, 1269-79.

9. Carlsson N, Bronmark C (2006) Size-dependent effects of an invasive herbivores snail (Pomacea canaliculata) on macrophytes and periphyton in Asian wetlands. Freshwat Biol 51, 695-704.

10. Fang L, Wong PK, Lin L, Lan C, Qiu J (2010) Impact of invasive apple snails in Hong Kong on wetland macrophytes, nutrients, phytoplankton and filamentous algae. Freshwat Biol 55, 1991-204.

11. Morrison WE, Hay ME (2011) Feeding and growth of native, invasive and non-indigenous alien snails (Ampullariidae) in the United States: invasive eat more and grow more. Biol Invasions 13, 945-55.

12. Lauhachinda N, Duangswasdi S, Sidhi S (1988) South America golden apple snails (Pomacea canaliculata) the new pest of aquatic plants. In: Kasetsart Univ Conference Report 26, pp 108-15. (in Thai).

13. Kwong K-L, Chan RKY, Qiu J-W (2009) The potential of the invasive snail Pomacea canaliculata as a predator of various life-stages of five species of freshwater snails. Malacologia 51, 343-56.

14. Schnorbach HJ (1995) The golden apple snail (Pomacea canaliculata Lamarck), an increasingly important pest in rice, and methods of control with Bayluscid®. Pflanzenschutz, Nachr Bayer 48, 313-46.

15. Carlsson N, Bronmark C, Hansson LA (2004) Invading herbivory: the golden apple snail alters ecosystem functioning in Asian wetlands. Ecology 85, 1575-80.

16. Wood TS, Anurakpongsatorn P, Chaichana R, Mahujchariyawong J, Satapanajaru T (2006) Heavy predation on freshwater bryozoans by the golden apple snail, Pomacea canaliculata Lamarck, 1822 (Ampullariidae). Nat Hist J Chula Univ 6, 31-6. 